\title{
EORTC Lung Cancer Group survey on the definition of NSCLC synchronous oligometastatic disease
}

Citation for published version (APA):

Levy, A., Hendriks, L. E. L., Berghmans, T., Faivre-Finn, C., GiajLevra, M., GiajLevra, N., Hasan, B., Pochesci, A., Girard, N., Greillier, L., Lantuejoul, S., Edwards, J., O'Brien, M., Reck, M., Besse, B., Novello, S., Dingemans, A-M. C., \& EORTC Lung Cancer Group (2019). EORTC Lung Cancer Group survey on the definition of NSCLC synchronous oligometastatic disease. European Journal of Cancer, 122, 109-114. https://doi.org/10.1016/j.ejca.2019.09.012

Document status and date:

Published: 01/11/2019

DOI:

10.1016/j.ejca.2019.09.012

Document Version:

Publisher's PDF, also known as Version of record

Document license:

Taverne

Please check the document version of this publication:

- A submitted manuscript is the version of the article upon submission and before peer-review. There can be important differences between the submitted version and the official published version of record.

People interested in the research are advised to contact the author for the final version of the publication, or visit the DOI to the publisher's website.

- The final author version and the galley proof are versions of the publication after peer review.

- The final published version features the final layout of the paper including the volume, issue and page numbers.

Link to publication

\footnotetext{
General rights Owners
rights.

- You may freely distribute the URL identifying the publication in the public portal. please follow below link for the End User Agreement:

www.umlib.nl/taverne-license

Take down policy

If you believe that this document breaches copyright please contact us at:

repository@maastrichtuniversity.nl

providing details and we will investigate your claim.
}

Copyright and moral rights for the publications made accessible in the public portal are retained by the authors and/or other copyright owners and it is a condition of accessing publications that users recognise and abide by the legal requirements associated with these

- Users may download and print one copy of any publication from the public portal for the purpose of private study or research.

- You may not further distribute the material or use it for any profit-making activity or commercial gain

If the publication is distributed under the terms of Article $25 \mathrm{fa}$ of the Dutch Copyright Act, indicated by the "Taverne" license above, 


\title{
EORTC Lung Cancer Group survey on the definition of NSCLC synchronous oligometastatic disease ${ }^{\text {tr }}$
}

\author{
Antonin Levy ${ }^{\text {a,b,c, }{ }^{*} \text {, Lizza E.L. Hendriks }}{ }^{c, d}$, Thierry Berghmans ${ }^{e}$, \\ Corinne Faivre-Finn ${ }^{\mathrm{f}}$, Matteo GiajLevra ${ }^{\mathrm{c}, \mathrm{g}}$, Niccolò GiajLevra ${ }^{\mathrm{c}, \mathrm{h}, \mathrm{i}}$, \\ Baktiar Hasan ${ }^{j}$, Alessia Pochesci ${ }^{\mathrm{j}}$, Nicolas Girard ${ }^{\mathrm{k}, 1}$, Laurent Greillier ${ }^{\mathrm{m}}$, \\ Sylvie Lantuéjoul ${ }^{\mathrm{n}, \mathrm{o}}$, John Edwards ${ }^{\mathrm{p}}$, Mary O'Brien ${ }^{\mathrm{q}}$, Martin Reck ${ }^{\mathrm{r}}$, \\ Benjamin Besse ${ }^{\mathrm{b}, \mathrm{s}}$, Silvia Novello ${ }^{\mathrm{t}}$, Anne-Marie C. Dingemans ${ }^{\mathrm{d}, \mathrm{u},{ }^{* *}}$ On \\ behalf of the EORTC Lung Cancer Group (EORTC LCG)
}

\footnotetext{
a Department of Radiation Oncology, Gustave Roussy, Institut D'Oncologie Thoracique (IOT), INSERM U1030 Molecular Radiotherapy, Université Paris-Saclay, F-94805, Villejuif, France

${ }^{\mathrm{b}}$ Univ Paris Sud, Université Paris-Saclay, F-94270, Le Kremlin-Bicêtre, France

c Young Investigators EORTC Lung Cancer Group (YI EORTC LCG)

${ }^{\mathrm{d}}$ Department of Pulmonary Diseases, GROW - School for Oncology and Developmental Biology, Maastricht University Medical Center+, Maastricht, the Netherlands

${ }^{\mathrm{e}}$ Department of Intensive Care and Oncological Emergencies \& Thoracic Oncology, Institut Jules Bordet, Université Libre de Bruxelles, Brussels, Belgium

${ }^{\mathrm{f}}$ Division of Cancer Sciences Institute of Cancer Sciences, University of Manchester, Christie NHS Foundation Trust, Manchester, UK

${ }^{\mathrm{g}}$ Respiratory Oncology Unit, Department of Thoracic and Vascular Disease, CHU Grenoble Alpes, Grenoble, France

${ }^{\text {h }}$ Radiation Oncology, Sacro Cuore Don Calabria Hospital, Negrar-Verona, Italy

${ }^{i}$ Department of Oncology, University of Turin, Torino, Italy

${ }^{\mathrm{j}}$ European Organisation for Research and Treatment of Cancer, Brussels, Belgium

${ }^{k}$ Institut Du Thorax Curie-Montsouris, Institut Curie, Paris, France

${ }^{1}$ University Lyon 1, Lyon, France

${ }^{\mathrm{m}}$ Multidisciplinary Oncology and Therapeutic Innovations, Assistance Publique Hôpitaux de Marseille, Aix Marseille University, Marseille, France

${ }^{\mathrm{n}}$ Department of Biopathology, Centre Léon Bérard UNICANCER, Lyon, France

${ }^{\circ}$ Université Grenoble Alpes, INSERM U1209/CNRS 5309 Institute for Advanced Biosciences, Grenoble France

${ }^{\mathrm{p}}$ Department of Cardiothoracic Surgery, Sheffield Teaching Hospitals NHS Foundation Trust, Sheffield, United Kingdom

${ }^{\mathrm{q}}$ Department of Medicine, Royal Marsden NHS Foundation Trust, London, UK

${ }^{\mathrm{r}}$ LungenClinic Grosshansdorf, Airway Research Center North, German Center for Lung Research, Grosshansdorf, Germany

${ }^{s}$ Department of Medical Oncology, Gustave Roussy, Institut D'Oncologie Thoracique (IOT), Gustave Roussy, Université Paris-Saclay, F-94805, Villejuif, France

${ }^{\mathrm{t}}$ Oncology Department, University of Turin, AOU San Luigi, Orbassano (TO), Italy

" Department of Respiratory Medicine, Erasmus Medical Center, Rotterdam, the Netherlands
}

\footnotetext{
This study was presented at WCLC Sept 2018, Toronto, Canada.

* Corresponding author: Department of Radiation Oncology, Gustave Roussy, Institut d'Oncologie Thoracique (IOT), INSERM U1030 Molecular Radiotherapy, Université Paris-Saclay, F-94805, Villejuif, France.

** Corresponding author: Department of Respiratory Medicine, Erasmus Medical Center, Rotterdam, the Netherlands

E-mail addresses: Antonin.LEVY@gustaveroussy.fr (A. Levy), a.dingemans@erasmusmc.nl (A.-M.C. Dingemans).
} 
Received 23 July 2019; received in revised form 25 August 2019; accepted 5 September 2019

Available online 28 October 2019

\section{KEYWORDS \\ Oligometastasis; Non-small cell lung cancer; Consensus}

\section{Introduction}

More than half of non-small-cell lung cancer (NSCLC) patients present with stage IV disease at diagnosis, and up to one-third of these patients have synchronous limited metastatic (oligometastatic) disease [1-4]. Synchronous oligometastatic disease (sOM) has been described as a distinct disease entity. This state is characterized by reduced metastatic potential with a limited number of metastatic sites, which makes the local treatment of each lesion possible [5]. Several single-arm phase 2 studies, and multiple retrospectives series reported favourable outcomes in highly selected sOM NSCLC patients who received local radical treatments (LRT) [4,6-11]. Three recent small (49-99 patients) randomized phase 2 studies showed that progression-free survival (PFS) (and overall survival [OS] in one study) [3] almost tripled with the addition of LRT to systemic therapy compared with systemic therapy alone in sOM NSCLC patients responding to first-line systemic therapy $[3,12,13]$.

There is, however, no consensus on what specific criteria constitutes SOM NSCLC. Of note, inclusion criteria for the previously cited studies were very different. The number of metastatic lesions, number of lesions per organ, type of organ specificity (e.g. inclusion of intracranial lesions or mediastinal lymph nodes) varied, resulting in difficultly comparing results of different trials. The European Organisation for Research and Treatment of Cancer Lung Cancer Group (EORTC-LCG) initiated a consensus process. A consensus group was formed aiming to agree on a common NSCLC sOM definition (sOM-d) that could be used in future clinical trials. A meeting to define the statement was planned and, as a preparation for this meeting, a systematic review [14], a survey, and real-life sOM NSCLC cases were distributed. Results of this preparatory work were used to identify areas of consensus and areas for further discussion (Fig. S1). The results of this survey are reported here.

\section{Methods}

\subsection{Study design and population}

An online (Google ${ }^{\circledR}$ form) survey developed by the EORTC-LCG was distributed on 14/12/2017 to all LCG 
and Radiation Oncology Group members of the EORTC. National cancer societies in Europe (medical oncology, pulmonology, radiation oncology) were also asked to circulate the survey to their members. Responses were collected until 19th February 2018.

\subsection{Description of the survey}

The survey was strictly confidential and anonymous. The questionnaire was divided into four sections: general questions, sOM-d, sOM staging, and expected benefit of local treatments. The questionnaire consisted of 31 questions, 4 were "tick all boxes that apply" type questions, and for all other questions, only one answer could be selected. An initial survey draft was reviewed by all EORTC LCG board members $(n=14)$ and by a panel of international experts in the field $(\mathrm{n}=12)$. The final questionnaire was modified according to these experts' comments and was designed to be completed in approximately $10 \mathrm{~min}$. A copy of the full survey is available in the Supporting Information.

\subsection{Statistical analysis}

The chi-squared test was used for dichotomous variables comparison (type of specialty: radiation oncologists vs. others). A two-sided P-value $<0.05$ was considered significant. All analyses were performed using software SPSS version 19.

\section{Results}

\subsection{General questions}

A total of 444 responses were collected. Belgium $(\mathrm{n}=62,14 \%)$, Italy $(\mathrm{n}=55,12 \%)$, UK $(\mathrm{n}=53,12 \%)$, Germany $(\mathrm{n}=47,11 \%)$, and the Netherlands $(\mathrm{n}=44$, $10 \%$ ) contributed most (Table S1). Physicians specialties were radiation oncologist: $55 \%(\mathrm{n}=242)$, pulmonologist: $15 \%(n=66)$, medical oncologist: $14 \%(n=64)$, surgeon: $7 \%(n=33)$, clinical oncologist: $7 \%(n=30)$, and others: $2 \%(\mathrm{n}=9)$. The main representing profession differed between countries with radiation oncologists constituting almost all responders in some countries (Germany: $\mathrm{n}=46 / 47,98 \%$, Switzerland: $\mathrm{n}=24 / 27,93 \%)$. Most $(78 \%, \mathrm{n}=346)$ physicians had $>5$ years of experience in treating NSCLC. Working environment was university hospital $(46 \%, \mathrm{n}=206)$, cancer centre $(23 \%, \mathrm{n}=103)$, general public hospital $(22 \%, \mathrm{n}=98)$, and private centre $(8 \%, \mathrm{n}=37)$.

\subsection{Definition of synchronous oligometastatic NSCLC}

A total of $81 \%(n=361)$ of physicians aimed to treat sOM NSCLC with curative intent and the same percentage acknowledged that the possibility to treat the patient with radical intent should be part of the sOM$\mathrm{d}$ (no difference according to specialty) (Fig. 1 and Table S2). The majority $(77 \%, \mathrm{n}=344)$ did not consider
Is it your aim to cure?

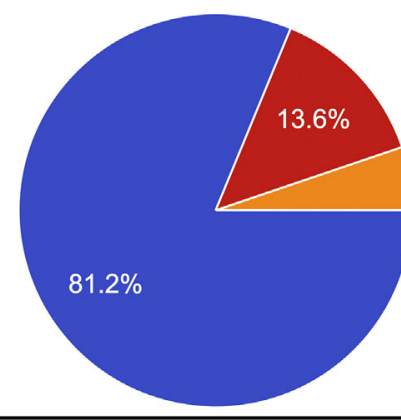

\section{Number of organs important?}
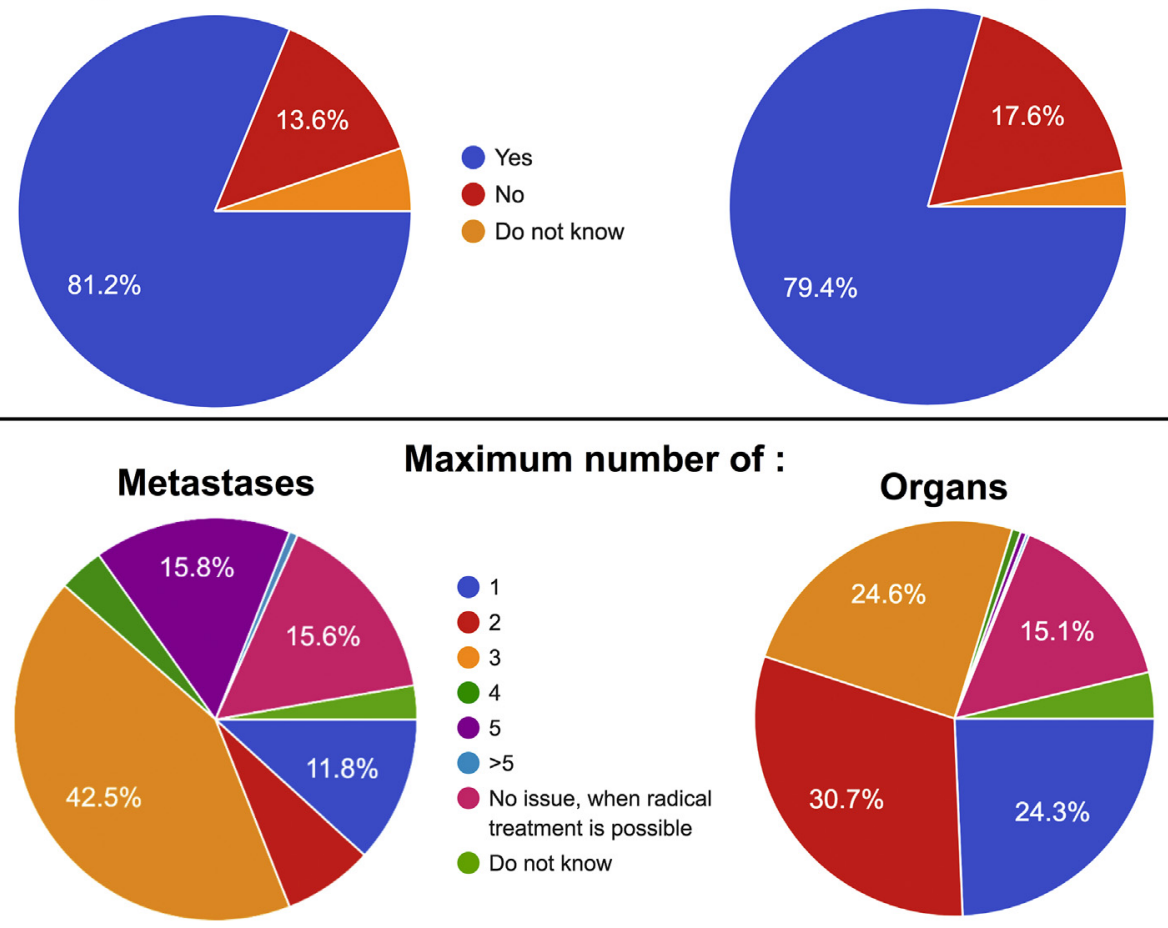

Fig. 1. NSCLC synchronous oligometastatic definition.

Abbreviations: NSCLC, non-small-cell lung cancer. 
the patients' mutational status in case of sOM-d. The maximum number of metastases allowed in the sOMd varied: $19 \%, 42 \%, 4 \%$, and $17 \%$ replied $\leq 2,3,4$, and $\geq 5$ metastases, respectively. Some $(16 \%)$ did not count as long as radical treatment was possible. $80 \%(\mathrm{n}=353)$ stated that the number of organs involved was important for the sOM-d, and most $(80 \%, \mathrm{n}=355)$ considered that only $\leq 3$ involved organs (excluding the primary tumour) should be considered sOM. $75 \%$ $(n=331)$ stated that the type of organs involved were important for the sOM-d. In general, physicians excluded organs that are not easily amenable to LRT (e.g. 316/331 [95\%] excluded meningeal and 269/331 [81\%] excluded pericardial metastases, Fig. S2). Most physicians $(69 \%, \mathrm{n}=309)$ acknowledged that it would be helpful to divide sOM into oligometastatic risk groups (Fig. S3). 384 (87\%) considered pulmonary metastasis (outside primary tumour, i.e. M1a) as a metastatic site. $317(72 \%)$ allowed mediastinal lymph node involvement in the sOM-d but only $22 \%(\mathrm{n}=70 /$ 317 ) of them counted mediastinal lymph node as a metastatic site. Of respondents favouring mediastinal lymph node, 195/317 (62\%) stated that there was no specific issue regarding the mediastinal lymph node volume/location as long as radical treatment was possible. Almost half of the respondents $(46 \%, \mathrm{n}=204)$ answered that the sOM-d should take into consideration total tumour volume (i.e. volume of primary + lymph nodes + metastases).

\subsection{Staging of synchronous oligometastatic NSCLC}

Most physicians completed sOM staging with brain magnetic resonance imaging (MRI) $(91 \%, \mathrm{n}=403)$, and
${ }^{18}$ fluorodeoxyglucose (FDG) positron emission tomography/computed tomography (PET-CT) $(98 \%, \mathrm{n}=437)$ (Fig. 2 and Table S3). For mediastinal lymph node staging, most respondents $(76 \%, \mathrm{n}=336 / 444)$ stated that histology/cytology should be obtained: $85 \%$ $(n=285 / 336)$ in cases where PET-CT shows suspected mediastinal lymph node or in case of a central primary tumour and 15\% (51/336) always performed mediastinal staging. Investigations to obtain mediastinal lymph node histology/cytology included EUS/EBUS (endoscopic ultrasound/endobronchial ultrasound) only (61\%, $\mathrm{n}=206 / 336)$ if representative material was obtained, and mediastinoscopy directly or after negative EUS/ EBUS in $25 \%(n=84 / 336)$. Pathology proof of metastatic disease was necessary in sOM for 315/444 (71\%) physicians. However, 131/315 (42\%) stated that they only obtained pathological proof when no lesion was visible on CT/MRI (i.e. FDG-positive lesion on PET but no tumour on CT or MRI). 256/369 (69\%) always aimed to obtain pathological proof (when safely possible) in cases where only one metastasis is present, and 113/369 $(21 \%)$ only when no lesion is identified on MRI/CT.

\subsection{Benefit of local treatments}

The preferred primary outcome parameter in clinical trials of sOM was OS $(73 \%, \mathrm{n}=325)$. Long-term OS $(45 \%, \mathrm{n}=200)$, PFS $(56 \%, \mathrm{n}=249)$, and quality of life $(54 \%, \mathrm{n}=238)$ were also selected ("tick all that apply" question). 299/444 (65\%) acknowledged that assessing local control after stereotactic ablative body radiotherapy (SABR) could be an issue (63\% [188/299] radiation oncologists vs. $37 \%$ [111/299] other specialties, $\mathrm{p}<0.001$ ); however, PFS remained a reliable end-point
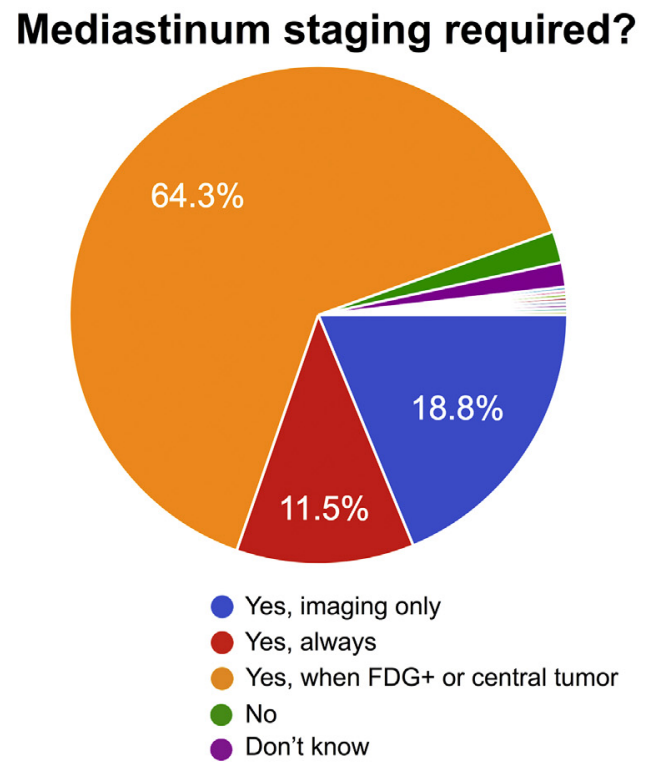

\section{Pathology proof always required?}

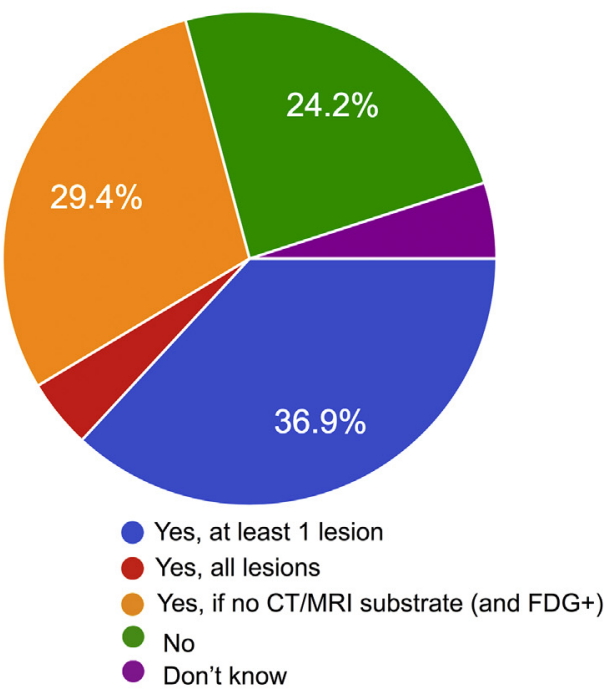

Fig. 2. Synchronous oligometastatic NSCLC staging.

Abbreviations: NSCLC, non-small-cell lung cancer; FDG, ${ }^{18}$ fluorodeoxyglucose; CT/MRI, computed tomography/magnetic-resonance imaging. 
for $62 \%(\mathrm{n}=274 / 444,65 \%$ [178/274] radiation oncologists vs. $35 \%$ [96/274] other specialties, p < 0.001).

\section{Discussion}

To the best of our knowledge, this is the first survey collecting data on sOM NSCLC. Our results highlight that for some items, consensus may easily be obtained. For example, $81 \%$ of respondents stated that the aim of OM treatment is cure, and that mandatory baseline imaging should include PET-CT and brain MRI for $98 \%$ and $91 \%$ of respondents, respectively. This fits in with recent recommendations by the EORTC to include brain MRI and PET-CT in the workup of sOM NSCLC patients [15]. In the recently published EORTC systematic review on sOM NSCLC, extended staging was indeed mandated in most of the studies [14]. However, several discussion points for the definition of sOM remain, and these mainly include numbers of metastases (it is suggested that SABR could also be of benefit in up to 10 brain metastases in selected patients) [15], organ type with metastasis (suggestion that patients with limited pleural disease could benefit from LRT) [16], and pathology requirements. This is also reflected in the systematic review [14], the three randomized trials $[3,12,13]$, and case series [17], as no uniform definition of sOM NSCLC could be retrieved. To standardize future clinical trials evaluating the benefit of metastasisdirected therapy in sOM, a common definition is required.

The preferred primary outcome measure in our survey was OS, but OS was the primary outcome in only one among three randomized phase II NSCLC OM trials $[3,12,13]$. Furthermore, it was recognized by $63 \%$ that evaluating local control after SABR could be problematic, and only $62 \%$ stated that PFS was a reliable end-point after LRT.

Limitations of this survey include [18], first, the absence of a response rate (respondents/total number of physicians contacted) because the survey was circulated by the national societies. Second, we did not subdivide our questions according to mutational status or histology. We also did not ask questions regarding the use of biological markers or the type of response to first-line systemic therapy as a selection criterion for LRT. These two criteria could help the clinician to better select patients more likely to benefit from LRT [19]. Third, we only included questions on sOM and excluded metachronous oligometastatic state or oligoprogressive disease, which hampers extrapolation to these two other states. Finally, selection bias is possible in our study as interested oncologists were more likely to respond to the survey, but we did have a large number of respondents and multiple represented disciplines. The respondents represent a specific population. Most respondents came from Western Europe and the networks used to send the questionnaire generally targeted a specific population (physician were members of scientific society or an organization that included patients in trials). It should, however, be emphasized that NSCLC sOM patients should preferably be treated or supervised by reference centre proposing clinical trials.

\section{Conclusion}

Although consensual answers were obtained, several issues remained unresolved and were discussed during a sOM-d consensus group meeting. A consensus sOM-d is proposed by the EORTC consensus group [20] to make future clinical trials more homogeneous and to guide clinicians in daily practice.

\section{Acknowledgements}

Authors would like to thank the cancer societies that helped distributing the survey to their members:

Belgium: BACTS (Belgian Association for Cardiothoracic Surgery); BVP-SBP (Belgian Society of Pulmonary Medicine); ABRO/BVRO (Belgian Association of Oncological Radiotherapy); ELCWP (European Lung Cancer Working Party).

Sweden: Swedish Lung Cancer Study Group (SLUSG).

Germany: DEGRO (German Society for Radiotherapy and Oncology) stereotactic group.

UK: BTOG (British Thoracic Oncology Group).

Israel: ISP (Israeli Society of Pulmonology); Israeli society for clinical oncology and radiation therapy.

The Netherlands: Dutch society for Cardio-Thoracic Surgery; LPRL (National Platform for Lung Tumors Radiotherapy); NVALT (Dutch Association of Physicians for Pulmonary Diseases and Tuberculosis).

Europe: EORTC LCG (European Organisation for Research and Treatment of Cancer Lung Cancer Group); ROG (Radiation Oncology Group); ESTRO (European Society for Radiotherapy and Oncology).

This publication was supported by a donation from the "La Ligue Nationale Contre le Cancer" from France through the EORTC Cancer Research Fund.

\section{Appendix A. Supplementary data}

Supplementary data to this article can be found online at https://doi.org/10.1016/j.ejca.2019.09.012.

\section{Conflict of interest}

Authors declare no conflict of interest and no funding related to this study.

LH (outside the current manuscript) received research funding Roche, Boehringer Ingelheim, AstraZeneca (all institution); served in the advisory board of 
Boehringer, BMS, (both institution, BMS also self); travel reimbursement: Roche, BMS (self); mentorship program with key opinion leaders: funded by AstraZeneca; fees for educational webinars: Quadia (self).

$\mathrm{BB}$ (outside the current manuscript) received institutional grants for clinical and translational research from Abbvie, Amgen, AstraZeneca, Biogen, Blueprint Medicines, BMS, Celgene, Eli Lilly, GSK, Ignyta, IPSEN, Merck KGaA, MSD, Nektar, Onxeo, Pfizer, Pharma Mar, Sanofi, Spectrum Pharmaceuticals, Takeda, and Tiziana Pharma.

$\mathrm{AD}$ (outside the current manuscript) served in the advisory board of BMS, MSD, Roche, Eli Lilly, Takeda, Pfizer, and Boehringer Ingelheim (all institution); research grant: BMS (institution).

\section{References}

[1] http://gco.iarc.fr/today/data/factsheets/cancers/15-Lung-factsheet.pdf (accessed 09/24/2018).

[2] Eberhardt WE, Mitchell A, Crowley J, Kondo H, Kim YT, Turrisi 3rd A, et al. International association for study of lung cancer staging and prognostic factors committee, advisory board members, and participating institutions. The IASLC lung cancer staging project: proposals for the revision of the $\mathrm{M}$ descriptors in the forthcoming eighth edition of the TNM classification of lung cancer. J Thorac Oncol 2015;10:1515-22.

[3] Gomez DR, Tang C, Zhang J, Blumenschein Jr GR, Hernandez M, Lee JJ, et al. Local consolidative therapy vs. Maintenance therapy or observation for patients with oligometastatic non-small-cell lung cancer: long-term results of a multiinstitutional, phase II, randomized study. J Clin Oncol 2019;37: 1558-65.

[4] Parikh RB, Cronin AM, Kozono DE, Oxnard GR, Mak RH, Jackman DM, et al. Definitive primary therapy in patients presenting with oligometastatic non-small cell lung cancer. Int J Radiat Oncol Biol Phys 2014;89:880-7.

[5] Hellman S, Weichselbaum RR. Oligometastases. J Clin Oncol 1995; 13:8.

[6] Collen C, Christian N, Schallier D, Meysman M, Duchateau M, Storme G, et al. Phase II study of stereotactic body radiotherapy to primary tumor and metastatic locations in oligometastatic non small-cell lung cancer patients. Ann Oncol 2014;25:1954-9.

[7] Hasselle MD, Haraf DJ, Rusthoven KE, Golden DW, Salgia R, Villaflor VM, et al. Hypofractionated image-guided radiation therapy for patients with limited volume metastatic non-small cell lung cancer. J Thorac Oncol 2012;7:376-81.

[8] Salama JK, Hasselle MD, Chmura SJ, Malik R, Mehta N, Yenice KM, et al. Stereotactic body radiotherapy for multisite extracranial oligometastases: final report of a dose escalation trial in patients with 1 to 5 sites of metastatic disease. Cancer 2012;118: 2962-70.

[9] De Ruysscher D, Wanders R, van Baardwijk A, Dingemans AM, Reymen B, Houben R, et al. Radical treatment of non-small-cell lung cancer patients with synchronous oligometastases: long-term results of a prospective phase II trial (Nct01282450). J Thorac Oncol 2012;7:1547-55.
[10] Sheu T, Heymach JV, Swisher SG, Rao G, Weinberg JS, Mehran R, et al. Propensity score-matched analysis of comprehensive local therapy for oligometastatic non-small cell lung cancer that did not progress after front-line chemotherapy. Int J Radiat Oncol Biol Phys 2014;90:850-7.

[11] Bauml JM, Mick R, Ciunci C, Aggarwal C, Davis C, Evans T, et al. Pembrolizumab after completion of locally ablative therapy for oligometastatic non-small cell lung cancer: a phase 2 trial. JAMA Oncol 2019 Jul 11. https://doi.org/10.1001/jamaoncol.2019.1449 [Epub ahead of print].

[12] Iyengar P, Wardak Z, Gerber DE, Tumati V, Ahn C, Hughes RS, et al. Consolidative radiotherapy for limited metastatic non-smallcell lung cancer: a phase 2 randomized clinical trial. JAMA Oncol 2018;4:e173501.

[13] Palma DA, Olson R, Harrow S, Gaede S, Louie AV, Haasbeek C, et al. Stereotactic ablative radiotherapy versus standard of care palliative treatment in patients with oligometastatic cancers (SABR-COMET): a randomised, phase 2, open-label trial. Lancet 2019;393:2051-8.

[14] GiajLevra N, Levra MG, Durieux V, Novello S, Besse B, Hasan B, et al. European Organisation for Research and Treatment of Cancer-Lung Cancer Group (EORTC-LCG). Defining synchronous oligometastatic non-small cell lung cancer: a systematic review. J Thorac Oncol 2019. https://doi.org/10.1016/j.jtho.2019.05.037. pii: S1556-0864(19)30458-7.

[15] DeSouza NM, Liu Y, Chiti A, Oprea-Lager D, Gebhart G, Van Beers BE, et al. Strategies and technical challenges for imaging oligometastatic disease: recommendations from the European Organisation for Research and Treatment of Cancer imaging group. Eur J Cancer 2018;91:153-63. Iida T, Shiba M, Yoshino I, Miyaoka E, et al; Japanese Joint Committee of Lung Cancer Registry. Surgical Intervention for Non-Small-Cell Lung Cancer Patients with Pleural Carcinomatosis: Results From the Japanese Lung Cancer Registry in 2004. J Thorac Oncol. 2015;10:1076-82.

[16] Yamamoto M, Serizawa T, Shuto T, Sato Y, Kawagishi J, Yamanaka K, et al. Stereotactic radiosurgery for patients with multiple brain metastases (JLGK0901): a multi-institutional prospective observationalstudy. Lancet Oncol 2014;15:387-95.

[17] Hendrik LEL, Doom C, Berghmans T, Novello S, Levy A, De Ruysscher D, et al. Defining Oligometastatic Non-Small Cell Lung Cancer (NSCLC): An Evolving Multidisciplinary Expert OpinionL. J Thoracic Oncol 2019;13:S446-7.

[18] Levy A, Faivre-Finn C, Hasan B, De Maio E, Berghoff AS, Girard N, et al. Young investigators EORTC lung cancer group (YI EORTC LCG). Diversity of brain metastases screening and management in non-small cell lung cancer in Europe: results of the european organisation for research and treatment of cancer lung cancer group survey. Eur J Cancer 2018;93:37-46.

[19] Lindsay DP, Caster JM, Wang K, Myung JH, Chen RC, Chera BS, et al. Prospective characterization of circulating tumor cells using a nanotechnology-based capture system in oligometastatic patients undergoing definitive radiation therapy. J Clin Oncol 2017. 15S:11533-11533.

[20] Dingemans AMC, Hendriks LE, Berghmans T, Levy A, Hasan B, Faivre-Finn C, et al. Searching for a definition of synchronous oligometastatic (sOMD)-NSCLC: a consensus from thoracic oncology experts. J Thorac Oncol 2019 Aug 6;2019. https: //doi.org/10.1016/j.jtho.2019.07.025 [Epub ahead of print]. 